\title{
Carapa guianensis Seed Oil
}

National Cancer Institute

\section{Source}

National Cancer Institute. Carapa guianensis Seed Oil. NCI Thesaurus. Code C107277.

The oil extracted from the seed kernels of Carapa guianensis. Carapa oil is used as a lamp oil, in the making of soap, and for topical skin application. 